\title{
Ceramic Design Based on the Need of Culture
}

\author{
Hui $\mathrm{Li}$ \\ School of Art and Design \\ Huanghe Science and Technology College \\ Zhengzhou, Henan, China 450063
}

\begin{abstract}
Goal: to research ceramic design based on the need of culture. Means: by collecting relative materials and on-thespot investigation to research what the mainstream culture requires ceramic design to do indeed, deeply analyzes culture default in ceramic design and fuses this default into new ceramic design by updating products and innovate design conception to create a more creative design. Conclusion: only the ceramic design that conforms to the age with rich connotation can meet the need of modern design and only the ceramic design with culture deposit as well as a high-end aesthetic temperament and interest caters to culture demand of people and meets the new requirement of the new stage.
\end{abstract}

Keywords-culture demand; ceramic design; background; factor; methods

\section{INTRODUCTION}

As people living standard rise, people's requirement for the quality of life is also increasing. Porcelains are widely used in and are closely related to people's daily life. Besides their own function values, they also have the function of aesthetics because the designers will satisfy physical and aesthetic demands from different people according to different culture demands when designing.

\section{CURRENT CONDITIONS OF CERAMIC DESIGN}

Ceramics are loved by people all over the world as historical art works, their development process in our country goes very long, so our country is given a laudatory name "ceramic powers". Nowadays, the materials are abnormally abundant, while the development of ceramic design in our country has a big gap comparing to that of ancient times, ceramic design is seriously lack of innovation. All of these ultimately result from our own culture is constantly invaded by foreign culture in the process of development. Our excellent culture is less and less used in the design, causing chaos in the ceramic design in our country [1] [2].

In terms of current conditions, there are also a lot of great designers who are researching our traditional excellent culture, but in this process, the designers must review their own problems and innovate the design on the basic of previous researches constantly.

The relationship between ceramic and culture is not only valued by domestic designers but also designers at abroad who even become forerunners in this field. For example, the Japanese always walk in the forefront. They research according to the actual conditions of their own cultural needs and extend study horizons to other countries overseas. And the western countries apply local cultural connotation in the ceramic design to an extreme, making the national spirit displayed incisively and vividly in the ceramic works [3] [4]. Such as ceramic works bird candy dishes from Turkey, the designer uses the bird-like picture of Roman civilization with modern ideas and methods of manufacture. The works is not only vivid, beautiful and nice, but also has the very high ornamental value and cultural connotation of art.

\section{RELATIONSHIP BETWEEN CERAMIC AND CULTURE}

Culture contains logic and cause and effect. It is the fruit of human spirit and the symbol of human intelligence. We cannot explain what culture is easily. But as the fruit of culture, ceramic, is the symbol of culture and is also a pattern of manifestation. Utensils themselves contain deep cultural connotation and rich time spirit. Their implicit stealth and profound meanings are worth thinking and researching by descendants. We can say that ceramics are not only the tools for a better life from they come into being, but also mirrors to reflect social phenomena and the spiritual appearance at that time. Ceramics both witness the history and record the history. They are concrete forms of culture and are art activities of culture. As concrete objects, ceramics reflect human social environment and cultural atmosphere of the age. While other objects act as the carriers of culture in daily life. 错误! 未找到 引用源。. Such as the fire extinguishers, are red and appealing. As the color of extinguishers is similar to that of blood, it will make people feel nervous and dangerous. The fire extinguisher itself is colorful and is easily found, making it more convenient. Thus today's shape of fire extinguishers forms, which implies much contact with people in the spiritual level. It is the design of the integrated a variety of cultures together, is the process from concept of culture to a concrete object. And ceramics are the most beautiful, vivid and precious works of art in the process. Ceramics are made by human through constant experiments to survive in nature. After thousands of years of design, manufacture, development, burnish, they play the indispensable role in people's life in various dynasties. Just by the changes of the ceramics, we can see the epitome of history of several thousand years in China, and we can see people's life and era characteristics in various dynasties. Ceramic art, surpasses the boundary of art, contains more cultural connotation and contents of the literature about the history and culture apart from arts, which makes ceramic's beauty more deep and profound. 


\section{Ceramic Arts AND the DeVelopment of Culture}

China's cultural development history is a long poem. Its national culture constitution is not just nature but also activities of creation by constantly learning and practices of people in the nature. Creation activities, as it were, are the basis of most human daily behaviors, and behavior purpose of people. People create constantly and increase more thinking space on the basis of the creation making the goods more valuable, and convey the psychological activities and mental minds of creators better. [6]. Therefore, ceramics record the development process of Chinese culture and put forth new concept and ideas for the other arts as carriers. They are one kind of art forms to promote the development of culture.

\section{Cultural InNOvation OF CERAMic DESIGN}

\section{A. Express Spirits by Objects}

In western countries, people value individuality in aesthetics. But in our country, the beauty of individuality is not widely accepted. In Chinese traditional aesthetic concept, beauty of harmony and unity is real beauty. It was also because of this, many outstanding works of art in ancient China, has the overall characteristics of beauty, such as the "Riverside Scene at Qingming Festival ". Our ancient Chinese art forms value realism less while impressionism more. Works of art pursue how to express the mien, which influences the value of later generations for the transmission of culture. Inheriting the abstract culture, in other words, passing things of spirit level is of more importance. This vivid forms used in the ceramic design can't be too suitable. Under the influence of this thought, designers can research our country's culture and history more deeply to find out the heritage significance of the culture and put it into the ceramic design by ways with the significance of the times. In the design of other objects we can see this aesthetic concept commonly, with deep cultural deposits, simple but impressive. Such as the design of torch in 2008, the main body of design is Xiangyun, which represents man and nature, auspice and generosity in Chinese traditional culture, can express our traditional thoughts, spread Chinese excellent culture and manifest China's spirit of tolerance and culture better to foreigners by printing it on the torch. Besides the Xiangyun, designers apply paper, which is the first one of the four great inventions, and red, which represents our countries, to the design of torch. Mixing these factors together gives people a lot of space to image and has strong Chinese characteristics and culture deposits. When designing ceramics, designers can take the advantage of torch design to innovate and recreate their own design.

\section{B. Direct use}

In addition to materializing and conveying spirit of the culture, using its inherent form directly is also a good design method. Of course, this kind of direct use is not copying blindly, but fusing existing factors into the functions of ceramic and designing creatively to make the cultural connotation deeper. The method was used in the extension of The Louvre Museum in Paris, and the court of new Louvre Museum is similar to Pyramid, which manifests both cultural connotation and visual shock.

\section{Extension}

In Chinese traditional culture, we can see the extension of culture everywhere. For example, people's worship to religious culture extends the symbols of auspice and wellbeing. All of these new cultures are formed by extension while these new culture are exactly what people pursue continually. Therefore, if designers can extend existing culture and make it cater to the need of modern society on the basis of its original connotation, the works will be more popular. When extending the culture, designers must not extend casually. They must combine the current hot issues and people's practical demands to extend culture reasonably and vividly and make people resonate mentally. Thus, the extension is Scientific and suitable.

\section{Design Methods For Ceramics with Culture DEPOSITS}

\section{A. Making Design Thought Clear}

To make a ceramic with rich culture connotation, the designers must make concrete design thoughts and the position of a ceramic clear before production. First of all, to determine the key words in the whole design, that is what culture the design is based on, what kind of style to show the culture, what art ceramics design purpose is and how to make it more practical [9]. Then, designers can get down to primary design. What worth mention is, when determining the theme of the ceramic design that is choosing what kind of culture to carry on the design, designers must use the well-known and distinctive symbolic elements. Otherwise, the consumers may be confused about what the ceramic wants to express. Before designing, designers should conduct on-the-spot investigation and careful research on the chosen culture, conclude its historical development and current conditions, and make aesthetic principles clear, which is good for the whole design and connection between designers and consumers.

\section{B. Making Conceptual Thought Clear}

Conceptual thought stage is the most demanding stage for the ability of designers. In this stage, designers should take the practical demands of consumers as judging standard and investigate it carefully. The ceramics are different from other art works. As one kind of utensils, they should be practical besides the values of aesthetics and collection. Therefore, when doing conceptual thought, designers must not value ceramics' beauty and transmit of culture connotation while ignore improving their own functions. After this, designers can choose culture factors for the design. Taking the culture of Hunan as the theme, designers can understand and study it deeply and analyze its most distinctive characteristics. In the culture of Hunan, the most distinctive characteristics are bronze ware, Tujia brocade, Xiangxi blue printing cloth, Huagu opera and pimiento. Designers can choose one or two of them to conduct conceptual thought and make primary preparation for design.

\section{Conducting Shape Design}

Shape design decides the appearance and function as well as the value of aesthetics and art of the final ceramics. It can be 
said that this step is the most important for inherit of culture. In design process, designers should turn culture factors into concrete forms and put them on ceramics to express implicit words by their own body language. At the same time, designers should keep the functions of ceramics intact and make ceramics more beautiful and meaningful with the aid of culture factors. They should not pursue more skills and factors at the cost of destroying their functions.

\section{CONCLUSION}

Along with the rapid development of social economy, people's ways of life and production have been changed. The improvement of science and interweaving of kinds of cultures and folk arts make modern life more and more colorful. In China, the cultural demand in the design of ceramics has got more and more attention of the relevant professionals and industry status quo also shows great vitality. In later development, if designers research bravely, study carefully, innovate audaciously and practice constantly, they can design more and more excellent works surely. In this paper, the author discusses how to apply culture factors into ceramic design better with the hope of making a little contribution to the development of ceramic design.

\section{REFERENCES}

[1] Mo Yuhong, Excavating and connection of modern design factors in Huxiang culture[D].Changsha:Hunan Normal University, 2008

[2] Zhang Jie, Zhong Lei. Innovation and protection of intangible cultural heritage in Tianjin under the view of culture $[\mathrm{J}]$. packaging engineering, 2014, 35 (14):110.

[3] Li Ran. Thought characters and modern application of cars in the preQin period[D]. Changsha:Hunan University, 2008.

[4] Wang Weiwei, Hu Yukun, Jin Xin, etc. research and application on extracting modals in traditional culture design[J]. packaging engineering, 2014,35 (6):73

[5] Tian Zhongyang. Spirits of Huxiang culture and Hunan literature in 20th century[M]. Changsha:Yuelu press, 2000.

[6] Su Huicong. Tradition and modern go together-a discussion on the development characters of Japan industrial design[J]. China High Technology Enterprises, 2009 (12).

[7] Zhang Jiumei. A research on the development of tourist souvenirs based on the well salt culture[J]. packaging engineering, 2014, 35 (14):98.

[8] Yi Pingce. Cultural history of aesthetics in China-concerning Qin, Han, Wei, Jin and the Northern and Southern dynasties [J]. Ji'nan:Shandong pictorial publishing house, 2000.

[9] Song Xiao. Research and case study on Urban cultural gifts creative design in Zhuhai [J]. packaging engineering, 2014, 35 (14):102.

[10] Sun Fangyi. A discussion on the application of traditional culture factors in modern ceramic products design [D]. Jingde Town:Jingdezhen Ceramic Institute, 2012. 